\title{
Mindsets of Global CEOs from the Perspective of Filipino Executives and Managers
}

\author{
GENARO V. JAPOS \\ drgvjapos@yahoo.com \\ Liceo de Cagayan University
}

Date Submitted : November 26, 2007

Final Revision Accepted: January 15, 2008

\begin{abstract}
The study investigated the mindsets of global CEOs from the perspective of selected Filipino executives and managers. The research used the descriptive design. The study found that the ability to create a vision for the future and leading others towards the realization of that vision are the top two behaviors of a global CEO. Along with being a visionary leader come character and integrity, which are seen by others in terms of positive disposition and work attitude, good decision-making, and competitive adaptation. Filipino executives and managers admire global CEOs, such as Bill Gates and Jack Welch, who have vision, business achievement, and influence on others as evidenced by strong commitment to corporate social responsibility. Executive competence tempered by compassion and the ability to compete in a cross-cultural environment is a distinguishing feature of Filipino CEOs. Filipino executives rise from the ranks and encounter difficulties and challenges, but they possess resilience, character, and integrity to succeed. Quality of human capital is the organizations' defining character of leading edge. For Filipinos to become global CEOs, the ability to adapt to a foreign environment and the ability to learn new language are the competitive advantages along with character and competence.
\end{abstract}

Key words - mindsets, global CEOs, Filipino executives and managers 


\section{INTRODUCTION}

The vision of the graduate program of Liceo de Cagayan University spotlights on the development of the global Filipino learner who is equipped to manage an organization in any part of the world. This vision of global Filipino executive is also shared by private and public organizations as a means to make the Philippines in sync with the challenges of the Third Millennium. However, organizations have different levels of maturity and growth depending on the vision, passion, and competence of their top management particularly the CEO. Hence, the study examined the mindsets of global CEOs from the perspective of Filipino executives and managers.

\section{OBJECTIVES OF THE STUDY}

This qualitative study pursued the following objectives: (1) to describe the behaviors that characterize top-of-the-line global CEOs as perceived by selected Filipino executives and managers, (2) to determine the behaviors peculiar to Filipino CEOs, (3) to elicit the strategies that develop executive behavior, (4) to trace the life experiences that shape CEO behavior, (5) to find the organizations' leading edge and the strategy to maintain it, (6) to craft the mechanisms that address the executives' problem behaviors, and (7) to draw out the best practices that enhance CEO behavior.

\section{METHODOLOGY}

The study used the descriptive design, applying qualitative research technique that included oral interviews and onsite observation. Field interviewers collected data from 33 selected Filipino executives and managers of public and private sectors around the country. Table 1 shows the respondents' distribution.

Table 1. Distribution of the respondents of the study

\begin{tabular}{cccc}
\hline Group & Public & Private & Total \\
\hline Executives & 9 & 8 & 17 \\
Managers & 8 & 8 & 16 \\
Total & 17 & 16 & 33 \\
\hline
\end{tabular}

The Filipino executives and managers hail from Luzon (Ortigas City [2], Quezon City [2], Pasig City [1]] and Mindanao (Cagayan de Oro City [8], Malaybalay City [6], Bukidnon [7], Valencia [2], Misamis Oriental [2], Lanao del Norte [10], Butuan City [2]). They were purposively sampled based on their availability and organizational affiliation. This affiliation facilitated the appointments for the interview.

The public sector executives include governors, congressmen, mayors/vice mayors, regional directors, and school presidents. The managers include the middle level administrators of various offices. The private sector executives consist of school presidents/AVP and CEOs of private companies.

Professional field interviewers handled the data gathering process. They recorded the interviews using video camera, portable tape recorder, and digital camera. An interview schedule guided the discussion. The transcript of the interview was the basis of the analysis of the data. Appointments preceded the interviews. 


\section{RESULTS AND DISCUSSION}

As an overview, the objectives guided the qualitative analysis of the data. There is an attempt to connect the findings with the literature cited.

1. Behaviors that Characterize Top-of-the-Line Global CEOs. Drawn from 69 descriptions and filtered down to 52 behavior indicators, six behaviors emerged as characteristics of global CEOs.

Table 2. Summary of behaviors of global CEOs as perceived by selected Filipino executives and managers

\begin{tabular}{lcc}
\hline & Behaviors & Count \\
\hline Vision and discernment skills & 10 \\
People and leadership skills & 13 \\
Demonstration of character and integrity & 10 \\
Disposition and work attitude & 7 \\
Decision making and risk taking & & 6 \\
Competitive Adaptation & Total & 6 \\
\end{tabular}

Vision and Discernment. Filipino executives and managers put premium on vision and discernment. Global CEOs have clear vision of what they want to do. They articulate the vision, become much focused, and have very strong will to achieve it. They have a wide understanding of global trends, enabling them to read and foresee possible political and social complications and the solutions to address changes. They look beyond the present and plan for the future. They put things together and bring people to a particular mission. They learn from failures; hence, they have a strong sense of what will work. The findings gain support in the concept by Gereen (1999) that executives, being leaders, translate vision to reality and that their moral courage pursues their vision with passion and persistence. In fact, vision and discernment are integral to the conceptual function of the executive role (Cherrington 2004).

People Skills. Global CEOs are great team players who bring out the best in others. They are people centered or "makamasa." They delegate tasks and treat peers as partners. They have excellent public relations and provide the best for customers/ clients. They are approachable and are sensitive to the needs of others. They form good interpersonal relationships, have great listening skills, and demonstrate empathy. They listen to learn. People skills are necessary for participative management for unity of purpose and action. Hence, the success of the organization is a function of the employees' overall performance and the effectiveness of executive styles that propel them towards the realization of the organizations' vision and mission as espoused by Newstrom and Davis (2003).

Character and Integrity. They have good reputation. They are honest, trustworthy, and credible. They have commitment and honor their word. Supported by resourcefulness coupled with patience and humility, they have original ideas. The findings corroborate the theory of O'Toole (1996) that leadership characteristics include courage, integrity, authority, vision, passion and persistence. In fact, the most outstanding leadership manifestation is moral courage.

Competitive Adaptation. Global CEOs develop their competitive edge by mastering the environment. They are quick to changes by adapting to new technologies and techniques. They are profit driven and steadfast in their pursuit of excellence. 
They continue to learn and maintain their edge over the competitors. The findings are parallel to the concept of change adoption by Butaslac (2004) and Mair (2001) in which executives adapt to new opportunities.

Disposition and Work Attitude. They have positive attitude. They keep an open mind reflective of intelligence and competence. They have great eye for detail by being meticulous. They are serious in their job. They value time and are punctual in their appointments. This is validated in the study of Riga (2004) in which great importance is given to commitment to justice and equity, public interest, political neutrality, nationalism and patriotism, commitment to democratic ideas, and public service. In fact, Freeman (1998) observed that developed industries and organizations have a generally positive attitude towards change.

Decision Making and Risk Taking. Global CEOs are tough decision makers and firm in their judgment for the benefit and survival of their organizations. This prompted one executive to remark that "there is no room for a soft - hearted leader in a very competitive business climate." They do not crack under pressure for it is in those times of difficulties that their critical thinking as CEOs must stand out and be relied upon. This notion is similar to the concept of management of measuring as predictor of norms of conduct.

2. The Admired Global CEOs. The interviewees mentioned 19 personalities, 10 foreigners and 9 Filipinos. Only two foreigners are politicians (Bill Clinton and George Bush) while the rest are business executives. The most popular CEO is Bill Gates who is admired for his vision and competence to lead a global organization, impact on global technology, corporate social responsibility, and philanthropy. The others are Jack Welch of General Electric, Robert Goizueta of Coca-cola, Carlos Ghoom, Peter Brabeck, Steves Jacobs, Apple Mackintoch and Carlos Slim Helu (world's richest man, August 2007). The Filipino CEOs cited officials from the public sector and three personalities from the private sector; one of them is the Archbishop of Manila (Cardinal Rosales). The public officials are President Gloria Arroyo, former-President Joseph Estrada, Senators Escudero and Zubiri, and Secretaries Yap and Ebdane. Only Gokongwei, Henry Sy, and Lucio Tan come from the business sector. In this country, leadership seems to be associated with public governance as evidenced by the number of government officials mentioned. The interviewees look up to their government leaders as model CEOs.

3. Behavior Peculiar to Filipino CEOs. Filipino CEOs usually manage small organizations. They are intelligent, gifted, capable, innovative, and passionatecharacteristics that allow them to efficiently use available resources within their reach. They are very compassionate and sensitive to other people's feelings compared to foreigners. They have great cross-cultural skills that can bring many nationalities together. They can adapt to foreign cultures and even learn new languages fast, making them highly flexible. They demonstrate willingness to work hard and compete with the rest in the field. They have high sense of patriotism, makatao at makadiyos. On the other hand, Filipino CEOs in the public sector also tend to be conservative in their jobs, inclined to be familiar, play favorites, and give more attention to politics than facing the needs of the people.

4. Behaviors Desired Among Employees. The interviewees desire employees who have initiative and are honest, hardworking, team players, trustworthy, loyal, values driven, intelligent, and committed. They said that honest employees are easy to manage because they have good values. From the behaviors given, they prefer employees who have good character and intelligence, competitive, and have people skills. The data show that the kinds of behavior preferred by the CEOs and the managers match. 
5. Strategies to Develop Employee Behaviors. To bring out the desired behaviors among the employees, the following strategies are cited:

Training, Education and Development. These insure a critical mass of employees with competence and values.

Role Modeling. This allows the employees to emulate others and be behaviorally consistent.

Mentoring, Coaching and Guidance. These facilitate problem solving, growth, and life-enhancing skills. One interviewee said, "They must be taught to analyze their mistakes to avoid recurrence of the same mistakes."

Performance Appraisal. This allows the employees to determine their strengths and weaknesses as basis for improvement and the management to design appropriate interventions.

Promotions, Ranking and Rewards. Employees learn from their experiences and build themselves up for possible promotion. Recognition of performance motivates employees. Those who deserve shall earn rewards.

6. Behaviors that Distinguish the CEOs from the Managers. Cornelio S. Mapa of Robinsons Land Corporation said that the very distinguishing factor for employee's promotion is the capability and willingness to accept the challenges and responsibility the job offers. The higher the rank one gets the more teams one has to play with and coach. The greater the output and breadth of communication styles, the clearer the path for excellence.

Fr. Jose Ramon Villarin, President of Xavier University, opined that effective managers keep things done by bringing people to work together. The CEO provides for the vision, inspiration, and excitement.

Managers are implementers of the mission to achieve the vision. They are answerable to their superiors. They make decisions and give directions for their assigned work. The CEOs make the most important decisions and provide the directions that would affect the entire company.

Pointing out the difference between managers and CEOs, Dr. Corazon Raymundo, former Chancellor of the University of the Philippines said: "You can easily distinguish any of them from the way they do things, their line of thinking, their perception in life, and their work habits."

7. Keeping the Best Performing People from Leaving the Organization. As one executive put it: "Make them part of the hope and vision of the company." This was echoed by another executive saying, "Treat them as if they are part of your own family. Make them happy with their present job by giving challenges that would bring out the best in them, and give due recognition for meritorious achievement."

Most of the answers gravitated to rewards. Extrinsic rewards that can keep great performing people from leaving the organization include good remuneration commensurate to performance, additional fringe benefits, salary increase, vacations, provision for cellular phones and car, service incentive leaves, hospital/medical benefits, and allowances. Intrinsic rewards consist of recognitions, professional augmentation, and support for staff development. There are also psychic spiritual rewards.

Other motivating strategies to keep employees are good working environment, total quality humanitarian care, respect for individual's dignity, and personal relationship. Humane treatment of employees counts. One executive said, "They should be congratulated for whatever achievement they make, and should be encouraged to do better when they fail." This kind of treatment creates the psychological climate of the organization. "One assurance", said an AVP of a Jesuit University "is a job that they 
truly enjoy, a job that they find fulfillment, a job they find satisfaction, and a job that gives recognition for performance."

8. Life Experiences that Shape CEO Behavior. Difficult beginnings and failures are the common denominators among the CEOs success. A Harvard-trained CEO quipped: "I have been humbled by many failures, but I always found enough strength to get up as a strong person with enough confidence and courage to face greater responsibilities and adversities. But humble I will always be." This was echoed by the governor of Misamis Oriental who said, "Self sacrifice; serve the people more." A Regional Director of NEDA said, "I rose from the ranks. I know exactly the job of all employees. I had difficulties before in dealing with politics, but I survived it."

Managers' previous experiences in their positions could strategically place them next in rank to the CEO level. Rich work experience is an advantage according to the DPWH executive from Bukidnon. The wide range of work experience prepared him for the job. This assertion is affirmed by a bank executive from Ortigas City who said, "All that you have gone through when you were young determine where you will be. The failures that you have experienced provide you with the strength to survive and succeed."

An interviewee gave credit to his being compassionate and empathetic, suggesting that a desirable character gives one an edge for the CEO post. Meanwhile, being thrust into a new culture abroad can shape CEO behavior as revealed in the case of a young and newly selected Muslim governor from Lanao del Norte who considered significant his being independent in the States.

A humble beginning is also a significant factor. One school president and priest said, "My closeness with the people and awareness of their concerns and formation in the priesthood has shaped my behavior."

9. The Leading Edge of Organizations. The provincial governor of Lanao del Norte cited the unity between Christians and the Muslims is the leading edge of his local government unit. Values education, discipline, and quality education define the leading edge of a Catholic school, which considers participation and mission, not competition, as drivers of quality education. The willingness to take the risk to survive and the availability of resources to increase production help improve efficiency.

The courage to face competition, versatility to efficiently respond to challenges, resources needed to grow, and the people who will make it all happen are the precursors to becoming a leading edge organization. Other factors are high quality, innovation, and strong research and development programs. Stability also counts. Good quality education also defines leading edge. People managers who are new, young, and driven can push for the leading edge.

The findings reveal that high quality of human capital is the defining factor of leading edge.

10. Strategy to Sustain the Leading Edge. One executive declared," We are competitive in an already intense state of competition." People are involved in doing continuous improvement in the frontline. Competition is good because it draws the best in people. It is not the winning that counts but how people give their best. By delivering fast and efficient services, the leading edge can be maintained.

Human capital development is another strategy. One educator claimed that a school must scout for the best students to become faculty. People make the big difference. Achieving excellence is a sure way to sustain the leading edge. Provision of state-of-the-art technologies reinvents the service delivery that creates the leading edge. Customer intimacy in frontline service also defines leading edge. 
11. Mechanisms for Executive Development. The public organizations implement the Code of Ethical Standards under RA 6713. They also have a moral development program designed to professionalize the bureaucracy and cleanse it of graft and corruption. The Civil Service Commission also handles top level development programs. The adherence to norms of conduct has been cited by Riga (2004). Executives in the public sector must give importance to public interest, commitment to democratic ideas, nationalism and patriotism, justice and equity, political neutrality, responsiveness to public service, and simple living.

In the private organizations, only few have executive development programs. These are usually the big corporations that put premium on quality of executives and managers. Two corporate cases can be cited. Nestle Philippines Inc. focuses on leadership program, performance management development system, performance excellence program, management principles, and corporate human resource policy. Robinsons Land Corporation has performance management system, well-defined organizational relationships, job descriptions, and culture of communication and excellence. Another mechanism is instilling corporate pride by riding on the JG Summit brand, which gives employees the competitive advantage not just as a real estate development company but as part of a large organization of diverse business interests. Weihrich and Koontz (2000) declare that effective executive development programs influence the performance of organizations, particularly in the way the management does planning, organizing, staffing, leading, and controlling functions.

12. Best Practices that Enhance Executive Behavior. Common among organizations is Executive Development Program that provides for training, education, and development. Trainings include assimilation of the vision and mission and goals, values development, teamwork, supervision, balanced score card, strategic planning, and culture of excellence. Education includes advanced and specialized programs for job enhancement and preparation for higher responsibilities.

Another best practice is the promotion of a culture to develop people and enhance leadership potentials in the organization. This culture is needed to reinforce to a significant degree the management of change of the organization by the executives (Dimaporo 2004). Tracking system for monitoring of employee development is also done every year with comparative analysis of performance as a basis for coaching and development.

Mentoring and coaching system is another best practice wherein employees with leadership potentials work under high achievers in the higher rank level. The system prepares the employees for the job requirements in the next level, making them prepared to take on the responsibility anytime. Coaching solves the problem of unfilled position because no one is readily available. In fact, the employees' monitoring and feedback have a significant bearing on the management of change facilitated through collaboration and change of the organization's vision, mission, and goals. Monitoring enhances the circulation of information and communication through downward and upward directions.

Another best practice is a highly functional promotions system, which progressively rewards and recognizes meritorious achievement at all levels. This practice gives employees a hint that they have career advancement path. The Mission Directives Workplace brings best practices to the frontline. Regular dialogues between top management and middle management greatly help in shaping behavior. The culture of communication is another best practice. The presence of a local computer network infrastructure hastens organizational communication supported by landline 
and cellular phones, email, instant messaging, and regular meetings.

13. Problem Behaviors of Executives and Managers. In the public organizations, the recurring problem cited has to do with authoritarian style of leadership that imposes obedience rather than creative and critical thinking. Thus, the accountability falls on the executives since it is their decisions that are followed. Little input is solicited from employees. Another problem cited is the infrastructure mindset rather than on people development programs. Most executives would rather leave a legacy in the form of grand monuments even in the midst of poverty and hunger of their people.

In the private sector, the problems include complacency, lack of attention to details, imposing stiff disciplinary actions to perpetuate a culture of fear and blind obedience, and lack of effective supervision since executives are out more often. The lack of delegation stalls many of the scheduled activities.

Another problem is the lack of courage and open communication with insight on coaching skills. Executive turnover also is a problem since the departure of executives and the coming in of new ones change the culture of work, attitudes, and values. The presence of cliques to secure the power base of competing executives has been observed to be divisive. There are also people with difficult, if not toxic, personalities who contaminate the psycho-social climate of the organization.

14. Strategies in Dealing with Executive Problem Behaviors. Few of the organizations have systems in place for dealing with executive problem behaviors. More often, these concerns remain unchecked until there are serious repercussions that require change. Coaching for success training, team-building, dialogues, application of due process, and performance evaluation are among the strategies mentioned. Psychological tests such as projective techniques, emotional quotient, and multifactor personality questionnaire help in understanding better the executives and in determining how they can be helped.

Reorganization, reengineering, and reinventing strategies also help in defining where the executives could be optimally useful to the organization. Spreading power and authority empowers the employees down the line and increases their sense of accountability.

These strategies help executives to develop a commitment to a strong work ethic, integrity, honesty, and quality. Commitment is achieved by building personal relations based on trust, and promoting personalized and direct way of dealing with each other. This is a more pragmatic than dogmatic approach to business that brings openness and curiosity. The approach instills pride and promotes loyalty to and identification with the company.

\section{CONCLUSIONS}

The ability to create a vision for the future and leading others towards the realization of that vision are the top two behaviors of a global CEO as perceived by selected Filipino executives and managers. Along with being a visionary leader come character and integrity, which are seen by others in terms of positive disposition and work attitude, good decision-making, and competitive adaptation. CEOs are the visionary leaders while managers are translators of the vision; CEOs define the vision while managers implement the mission. The best way to keep potential people from leaving the organization is to treat them with dignity and respect as partners and to provide them with adequate compensation and incentives to sustain their enthusiasm for work. Filipino executives rise from the ranks and encounter difficulties and 
challenges, but they possess resilience, character, and integrity to succeed.

Filipino executives and managers admire global CEOs, such as Bill Gates and Jack Welch, who have vision, business achievement, and influence on others as evidenced by strong commitment to corporate social responsibility. Executive competence tempered by compassion and the ability to compete in a cross-cultural environment is a distinguishing feature of Filipino CEOs.

Employees who are honest, hardworking, synergistic, trustworthy, and loyal are most valued in the workplace. Character takes precedence over competence. A highly functional, sustainable, and responsive human resource development program guarantees the development of employee behavior.

Quality of human capital is the organizations' defining character of leading edge. This is developed and sustained by a strong and supportive human resource program for people development.

The study confirms the theory of executive roles and functions by Cherrington (2004), particularly on the conceptual, technical, interpersonal, informative, and decisional functions. Integral to conceptual function is the executive ability to create a clear vision and transform it to reality.

The study also affirms the confluence of factors that affect the effectiveness of the executives. The study generated evidence on the adoption of participative management to create a powerful synergy that can draw people together for unity of purpose and action as advocated by Newstrom and Davis (2003). This is supported by empowerment of employees espoused by Tappen (2005). The global executives are perceived to delegate their tasks and provide resource support.

Competitive adaptation as an attribute of global CEOs gains support in the concept advanced by Mair (2001), which views change adaptation as a structural change response and the cumulative individual reaction to new situations. In the study, executives thrive best in mastering the environment, quickly adjusting to new cultures and learning languages and rising from the ranks.

The assertion of Phillips (2005) is affirmed in this study that leadership behavior of the global executive is the keystone that holds organization together. It is indeed a strong leadership that translates vision to reality (Gereen, 1999). Moral courage is the ultimate defining character of global CEOs (O'Toole, 1996).

\section{LITERATURE CITED}

Butaslac, I. V. (2004). Work commitment and change adoption in relation to customers' satisfaction on the services and facilities of the port of Cagayan de Oro: a basis for development and institute program. Dissertation (DM). Liceo de Cagayan University.

Cherrington, D. J. (2004). Organizational behavior: the management of individual and organizational performance. (Revised Edition). Boston: Allyn and Bacon.

Certo, S. C. (2006). Supervision: quality and diversity through leadership. (Revised Edition). New York: Mc Grawhill and Company.

Dimaporo, D. G. (2004). Organizational culture and goal setting as correlates of management of Environmental Management Bureau in Region 10: a basis for an organizational reengineering. Dissertation (DM). Liceo de Cagayan University.

Freeman, D. (1998). Leadership and society: issues in assessment, conflict and choice. Chicago. Mc Ney Publishing Company.

Gereen, F. (1999). Achieving competence, success and excellence. Chicago: Erwin 
Mair, L. (2001). Social change. London: The Altroit Press.

Mondy, M. (2001). Human resources management. Boston: Allyn and Bacon.

Newstrom, J. and Davis, K. (2003). Leadership: theory and practice. New York: The Haworth Information Press.

O'Toole, J. (1999). Organization and management: (Revised Edition). Philippines: IAME Design Studio.

Philips, O. (2005). Human resources management. (6 $6^{\text {th }}$ Edition). New York: Oxford University Press.

Riga, C. (2004). Management skills and team building capability as correlates of the extent of adherence to the norms of conduct of the executives of the government agencies of the Autonomous Region in Muslim Mindanao: a basis for a training program. Dissertation (DM). Liceo de Cagayan University.

Tappen, R. M. (2005). Leadership and management. New York: Mc Grawhill and Company.

Weihrich, H. and Koontz, H. (2005). Management: a global perspective. $\left(11^{\text {th }}\right.$ Edition). Philippines: McGraw-Hill Education (Asia). 